SHEs: Conference Series 1 (1) (2018) 85-91

\title{
URGENCY OF PARTICIPATION OF PARENTS IN DEVELOPING POSITIVE CULTURE IN ELEMENTARY SCHOOLS
}

\author{
Atsani Rohmatun Nisa', Ratih Laila Istiqomah \\ Universitas Sebelas Maret \\ sun_nieza.moedz@yahoo.co.id
}

\section{Article History}

accepted 09/07/2018

approved 01/08/2018

published 17/09/2018

Keywords

budaya positif, partisipasi orang tua, sekolah dasar

\begin{abstract}
Artikel ini bertujuan untuk mendeskripsikan pentingnya pastisipasi orang tua dalam menciptakan budaya positif di sekolah dasar. Bentuk penelitian ini deskriptif kualitatif. Pengumpulan data melalui lembar observasi dan lembar wawancara. Data bersumber dari hasil observasi, hasil wawancara dan hasil dokumentasi. Data yang diperoleh dikumpulkan dan diolah menggunakan teknik analisis kualitatif. Hasil penelitian menunjukkan bahwa partisipasi orang tua sangat diperlukan untuk menciptakan dan meningkatkan budaya positif di sekolah dasar. Adanya kerjasama yang kuat antara pihak sekolah dan orang tua mampu mempengaruhi keberhasilan terciptanya budaya positif yang tidak hanya berdampak pada sekolah tetapi juga pada orang tua dalam memberikan dukungan positif pada peserta didik. Bentuk partisipasi orang tua yaitu melakukan kegiatan rutin yang diadakan oleh pihak sekolah, seperti: Kajian Kelas, Family Gathering, Parenting skill, Family Day, Sarasehan Ramadhan.
\end{abstract}

Social, Humanities, and Education Studies (SHEs): Conference Series https://jurnal.uns.ac.id/shes

p-ISSN 2620-9284 e-ISSN 2620-9292 
SHEs: Conference Series 1 (1) (2018) 85-91

\section{PENDAHULUAN}

Pendidikan adalah usaha sadar dan terencana untuk mewujudkan suasana belajar dan pembelajaran agar peserta didik secara aktif mengembangkan potensi dirinya untuk memiliki kekuatan spiritual keagamaan, pengendalian diri, kepribadian, kecerdasan, akhlak mulia serta keterampilan yang diperlukan dirinya, masyarakat, bangsa dan negara. Pendidikan merupakan salah satu aspek dalam peningkatan mutu sumber daya manusia. Pendidikan memiliki peran yang signifikan dan menjadi peran utama dalam penyiapan sumber daya manusia yang berkualitas. IImu pengetahuan dan teknologi serta kualitas sumber daya manusia merupakan faktor kunci dalam menentukan daya saing suatu bangsa.

Undang Undang No. 20 tahun 2003 tentang Sistem Pendidikan Nasional bab II pasal 3 menyatakan bahwa "Pendidikan Nasional berfungsi untuk mengembangkan kemampuan dan membentuk watak serta peradaban bangsa yang bermartabat dalam rangka mencerdaskan kehidupan bangsa,bertujuan untuk berkembangnya potensi peserta didik agar menjadi manusia yang beriman dan bertakwa kepada Tuhan Yang Maha Esa dan berakhlak mulia, sehat,berilmu,cakap, kreatif, mandiri dan menjadi warga Negara yang demokratis serta bertanggung jawab.

Pada saat ini mutu pendidikan belum mengalami peningkatan secara signifikan. Pertama, kebijakan penyelenggaraan pendidikan masih berorientasi pada keluaran pendidikan (output), terlalu memusatkan pada masukan (input), dan kurang memperhatikan pada proses pendidikan; Kedua, penyelenggaraan pendidikan disinyalir kurang menyentuh kebutuhan masyarakat dan kurang sesuai dengan kondisi sekolah setempat; Ketiga, selama ini partisipasi masyarakat terutama orang tua peserta didik dalam penyelenggaraan pendidikan hanya terbatas pada dukungan dana. Padahal partisipasi mereka sangat penting di dalam proses pendidikan antara lain: pengambilan keputusan, pemantauan penyelenggaraan pendidikan di sekolah, evaluasi, akuntabilitas sekolah, dan lain-lain.

Sekolah sebagai sebuah lembaga tempat penyemaian ilmu yang terorganisasi secara formal, sangat berperan penting dalam meningkatkan kualitas dan jati diri seseorang, mengubah latar belakang seseorang menjadi lebih baik, sekolah yang baik tidak hanya mengubah anak didiknya menjadi pribadi yang berpendidikan akan tetapi juga turut mengubah lingkungan bermasyarakat menjadi yang lebih baik. Sekolah sebagai sistem sosial merupakan bagian integral dari sistem sosial yang lebih besar, yaitu masyarakat.

Henderson dan Berla (2004) menyatakan manfaat atau keuntungan partisipasi orang tua dalam pendidikan anak menunjukkan bahwa tolok ukur paling akurat atas sesuatu yang didapat oleh peserta didik di sekolah bukanlah berupa pendapatan atau status sosial, namun lebih luas dari itu, yaitu bahwa keluarga dari para peserta didik akan menjadi mampu: (1) menciptakan suatu suasana yang nyaman sehingga mendorong lahirnya sebuah pembelajaran, (2) menunjukkan harapan yang tinggi akan sesuatu yang nantinya didapatkan oleh anak-anak mereka dan pengharapan yang tinggi akan pekerjaan anak-anak itu pada masa depan mereka, dan (3) terlibat dalam pendidikan anak mereka, baik di sekolah maupun di masyarakat.

Partisipasi atau keterlibatan masyarakat lebih khusus orang tua peserta didik yang terencana secara efektif, dan diimplementasikan dengan baik, akan menghasilkan manfaat yang substansial bagi peserta didik, pendidik, masyarakat secara luas, dan tentunya berimbas pada pencapaian mutu sekolah. Partisipasi orang tua mendukung pembangunan pendidikan. Partisipasi orang tua sangat strategis bagi pengembangan kecerdasan atau kemampuan anak dalam pembentukan kepribadian yang utuh. Hal inilah yang menjadi dasar bagi fondasi pembentukan intelektual, emosional, spiritual dan moral anak. 
SHEs: Conference Series 1 (1) (2018) 85-91

Sejatinya pendidikan adalah sebuah proses yang melibatkan banyak komponen. Tidak hanya tanggungjawab pemerintah tetapi juga tanggungjawab masyarakat dan orang tua.Tugas utama orangtua dalam pendidikan adalah sebagai peletak pondasi dasar. Dalam kaitannya dengan pendidikan orangtua bisa mendidik anak dengan menjadi suri tauladan yang baik sebagaimana prinsip yang telah dikemukakan oleh Ki Hajar Dewantara yaitu ing ngarso sung tulodo, dan menanamkan kebiasaan-kebiasaan baik sehingga menjadi karakter yang mulia. Akhirnya, dapat dikatakan bahwa pendidikan sebagai proses memanusiakan manusia mestinya tidak boleh alpa memberikan pendidikan dan pengalaman sejak dini, jika tidak diyakini akan sulit mewujudkan generasi emas yang sesungguhnya. Generasi emas yang dimaksudkan adalah generasi yang tidak saja cerdas, kompeten, memiliki skill kompetetif, tetapi yang lebih penting lagi adalah memiliki karakter dan kebangsaan.

Sebagai wujud melaksanakan amanat dari undang-undang maka lembaga sekolah harus berupaya menciptakan suatu budaya positif bagi siswa, agar sekolah dapat menjadi tempat yang kondusif bagi penyemaian dan pengembangan watak optimisme, mengembangkan penalaran, pencerahan akal budi, membekali ketrampilan, dan sikap yang dibutuhkan untuk menjadikan siswa yang jujur, sopan santun, kreatif produktif, mandiri, dan bermanfaat bagi sesamanya. Karena sekolah merupakan salah satu tempat siswa berinteraksi, selain lingkungan keluarga dan masyarakat untuk melakukan proses sosialisasi, yaitu sosialisasi nilai, pengetahuan, sikap, dan keterampilan. Selain itu menurut Stolp (1994: 2), budaya positif juga berdampak pada peningkatan motivasi dan prestasi belajar peserta didik serta kepuasan kerja dan produktivitas guru. Untuk itu, sekolah sebagai sebuah institusi perlu dikelola dengan cara-cara pengelolaan yang baik.

Prinsip pengelolaan sekolah menurut Habegger (2008: 43) yaitu ada dua prinsip yang harus digunakan agar menciptakan budaya sekolah yang positif yaitu menciptakan rasa memiliki dan memberikan tujuan yang jelas untuk semua pihak yang terlibat dalam pengembangan budaya sekolah baik guru, peserta didik maupun orang tua.

Espericueta (2015: 1) menyatakan bahwa keterlibatan orang tua penting karena menciptakan kolaborasi positif dan saling menghormati antara orang tua dan sekolah. Semakin banyak orang tua merasa terlibat, dihargai, dan dianggap sebagai mitra, semakin mereka akan mendukung sekolah dan mendorong anak mereka untuk berprestasi.

Mutch \& Collins ( 2012: 179) menguatkan bahwa faktor kunci terkait untuk menciptakan budaya positif di sekolah adalah keterbukaan yang tulus terhadap orang tua dan keterlibatan masyarakat, aksesibilitas personel sekolah, dan praktik-praktik yang inklusif terhadap keanekaragaman.

\section{METODE}

Jenis penelitian yang digunakan yaitu penelitian deskriptif kualitatif. Penelitian deskriptif merupakan penelitian yang lebih mengarah pada pengungkapan suatu masalah atau keadaan sebagaimana adanya dan mengungkapkan fakta-fakta yang ada, walaupun kadang-kadang memberikan interpretasi atau analisis.( Tika, $2005:$ 4). Penelitian ini berupaya untuk memperoleh gambaran mengenai urgensi partisipasi orang tua dalam pengembangan budaya positif di sekolah dasar.

Penelitian ini dilaksanakan di SDIT Insan Kamil. Subjek penelitian ini adalah kepala sekolah, guru, siswa dan orang tua SDIT Insan Kamil. Teknik sampling yang digunakan dalam penelitian ini adalah dengan teknik Purposive sampling dan Snowball sampling .

Alat pengumpulan data yang digunakan dalam penelitian ini berupa lembar observasi dan lembar wawancara untuk kepala sekolah, guru, siswa dan orang tua 
SHEs: Conference Series 1 (1) (2018) 85-91

mengenai manfaat dan bentuk-bentuk partisipasi orang tua untuk meningkatkan budaya positif di sekolah.

Teknik pengumpulan data dalam penelitian ini menggunakan teknik pengamatan, wawancara, dan dokumentasi. Data yang diperoleh dari penelitian ini berupa data kualitatif. Data yang terkumpul dianalisis menggunakan teknik analisis kualitatif yang digunakan untuk menganalisis urgensi partisipasi orang tua dalam pengembangan budaya positif di sekolah dasar.

Analisis data kualitatif menggunakan tiga alur kegiatan sesuai dengan pendapat Miles dan Huberman (Sugiyono, 2017: 338-35) yaitu reduksi data, penyajian data dan penarikan kesimpulan.

\section{HASIL DAN PEMBAHASAN}

Penelitian ini melalui tiga tahap sesuai pendapat Miles dan Huberman (Sugiyono, 2017: 338-35) yaitu reduksi data, penyajian data dan penarikan kesimpulan. Data diperoleh melalui observasi, wawancara dan dokumentasi. Teknik sampling yang digunakan dalam penelitian ini adalah dengan tenik Purposive sampling dan Snowball sampling. Pada teknik Purposive sampling peneliti mengobservasi dan wawancara terhadap sumber yang dianggap lebih tahu yaitu guru, karena guru dianggap paling mengetahui dan dekat dengan permasalahan pada diri peserta didik. Sebagai penguat dan pelengkap data yang diperoleh dari guru, maka peneliti menggunakan teknik snowball sampling adalah teknik pengambilan sumber data yang pada awalnya jumlahnya sedikit, lama-lama menjadi besar. Subjek penelitian lain yaitu kepala sekolah, orang tua dan perwakilan siswa.

Dari hasil observasi, wawancara dan dokumentasi menunjukkan urgensi partisipasi orang tua dalam pengembangan budaya positif di sekolah dasar, diantaranya sebagai berikut:

\section{Kepala sekolah}

Tingginya partisipasi dan kerjasama orang tua dengan sekolah sangat berpengaruh bagi pengembangan dan sosialisasi budaya positif yang dicanangkan oleh sekolah, ini tercermin dari kedisiplinan siswa yang meningkat dan kenyamanan siswa saat berada di sekolah. Akibat dari partisipasi sekolah juga membawa dampak meningkatnya mutu sekolah, hal ini terbukti SDIT Insan Kamil yang pada tahun 2005 hanya menerima sebanyak 53 peserta didik kemudian hanya dalam kurun waktu 13 tahun yaitu di tahun 2018, peserta didik di SDIT Insan Kamil sudah mencapai 760 peserta didik. Hal ini sesuai dengan pengujian yang dilakukan oleh Zubaidah (2015: 182) yang menemukan bahwa budaya sekolah juga berpengaruh positif terhadap mutu pendidikan.

\section{Guru}

Pelibatan dan keterbukaan orang tua dalam mencipatkan budaya positif di sekolah, sangat membantu guru dalam mengatasi masalah belajar dan pembentukan karakter peserta didik. Orang tua memberikan dorongan dan motivasi di rumah sehingga peserta didik dapat meningkatkan hasil belajar di sekolah. Selain itu beberapa budaya positif yang dijalankan di sekolah seperti ibadah rutin dan akhlaq yang baik, dapat diteruskan dan menjadi kebiasaan mereka dalam keseharian, sehingga diharapakan kebiasaan baik tersebut dapat menjadi karakter dan watak positif dalam diri peserta didik yang dibawa hingga dewasa nanti.

\section{Orang tua}

Orang tua merasa senang dan memperolah manfaat dalam pelibatannya dalam pembentukan budaya positif di sekolah. Manfaat yang sangat dirasakan orang tua yaitu mempererat silaturahmi dan meningkatkan kelimuan tentang pendidikan anak. Silaturahmi yang terjalin tentunya tidak hanya dari pihak sekolah terhadap orang tua, tetapi juga antar orang tua, karena mereka terlibat dan rapat 
SHEs: Conference Series 1 (1) (2018) 85-91

bersama setiap sebulan sekali sehingga secara tidak langsung ikatan silaturahmi terjalin dengan erat. Selain itu ilmu orang tua semain meningkat, karena sekolah menghadirkan bebrapa pakar pendidikan bahkan ustadz yang memberikan wawasan kepada orang tua tentang tata cara mendidik anak dengan baik, sehingga melahirkan anak yang selamat dan berguna bagi agama, bangsa dan negara.

\section{Siswa}

Orang tua yang wawasananya meningkat tentunya akan berdampak positif dalam diri anak, hal ini terbukti dari hasil wawancara pada perwakilan peserta didik, mereka memperoleh motivasi dan dorongan yang positif di rumah sehingga mereka lebih semangat dalam belajar. Selain peningkatan dalam bidang akademik, siswa juga lebih terdorong untuk mengembangkan diri mereka pada kegiatan ekstrakulikuler, orang tua memberikan kepercayaan pada anak untuk mengikuti beberapa kegiatan sekolah walaupun kegiatannya sampai sore bahkan menginap di sekolah.

Pada saat di rumah mereka juga menyatakan ada beberapa kegiatan di sekolah yang juga menjadi kebiasaan di rumah, seperti shalat berjamaah, tilawah al-qur'an, bersedekah, budaya bersih, cinta lingkungan, menghargai sesama dll.

Berikut beberapa kegiatan SDIT Insan Kamil untuk meningkatkan pelibatan orang tua dalam membentuk budaya positif di sekolah:

\section{Kajian kelas}

Kajian kelas adalah sarana sekolah yang mewadahi dan mengembangkan potensi wali murid, guru, dan sekolah agar bisa meningkatkan efisiensi, efektifitas, produktivitas, kreatifitas, inovasi, mutu, dan relevansi pendidikan sekolah dan rumah (orang tua). Bentuk kajian kelas adalah pengajian bersama, sms tausyiah online, kajian, kerjasama pendayagunaan aset, memfasilitasi usaha penggalangan dana dan bentuk lainnya yang dianggap perlu. Kajian kelas dilakukan oleh tiap-tiap kelas, 1 bulan 1 kali dan dikoordinir oleh wali kelas bersama wali murid yang ditunjuk sebagai koordinator.

\section{Parenting skill}

Parenting skill merupakan kegiatan berupa seminar atau talkshow yang ditujukan kepada orangtua, untuk meningkatkan pemahaman tentang pendidikan anak serta agar terjadi sinergisitas antara orang tua dan sekolah.

\section{Family Gathering}

Family gathering adalah kegiatan yang dilaksanakan oleh siswa dan orangtua jenjang VI, menjelang pelaksanaan Ujian Nasional. Tujuan kegiatan ini adalah menyamakan "frekuensi" persiapan Ujian nasional antara sekolah dan rumah/orangtua serta meningkatkan kebersamaan antara orangtua dan anak.

\section{Family Day}

Family day adalah kegiatan yang diikuti oleh siswa, orang tua/wali murid jenjang I dan seluruh guru karyawan SDIT Insan Kamil secara bersamasama. Family Daymerupakan kegiatan tahunan yang bertujuan untuk meningkatkan keakraban antara guru dengan siswa maupun dengan orang tua/wali murid siswa baru.

\section{Sarasehan Ramadhan}

Sarasehan ramadhan adalah kegiatan yang diikuti oleh guru dan orang tua/wali murid yang dilakukan di sekolah/rumah salah satu siswa atau di sekolah pada waktu bulan ramadhan. Sarasehan merupakan sarana untuk menjalin silaturahmi yang kokoh antara sekolah (wali kelas/guru) dengan orang tua/wali murid. 


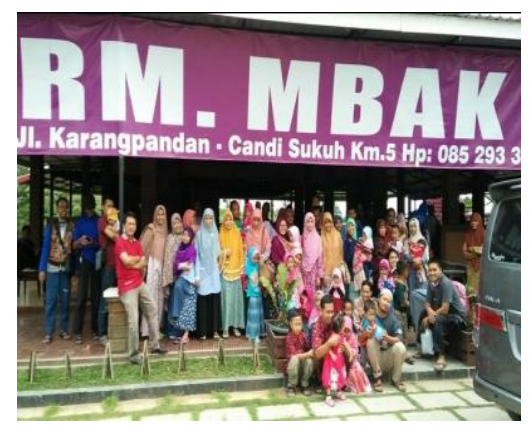

Family Gathering

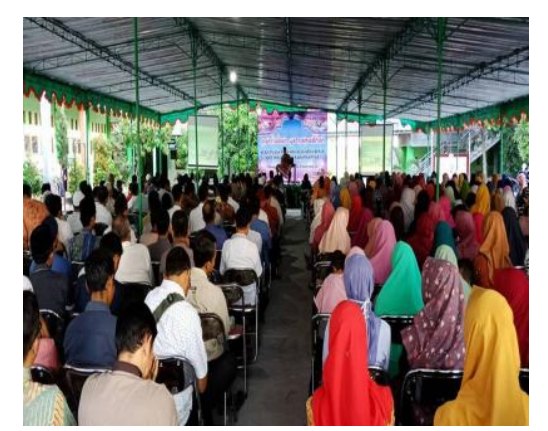

Sarasehan Ramadhan

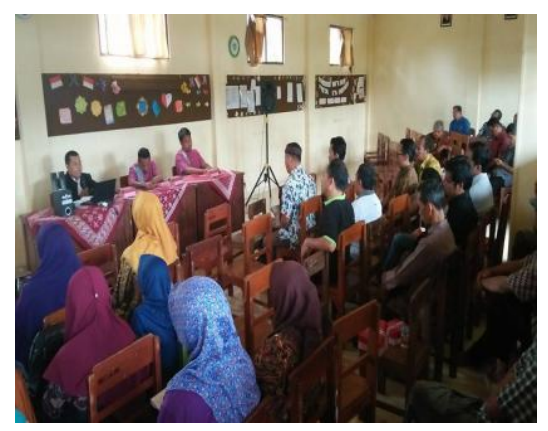

Kajian Kelas

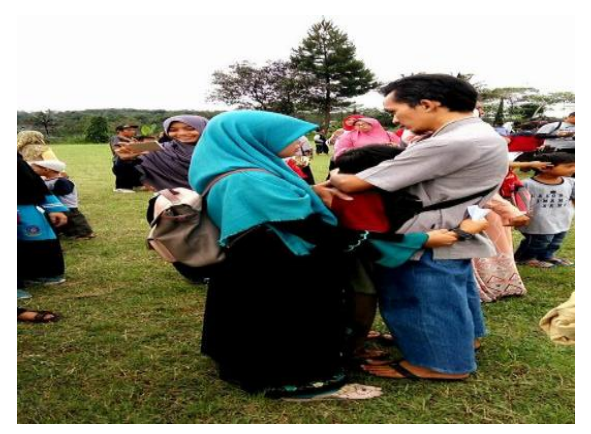

Family Day

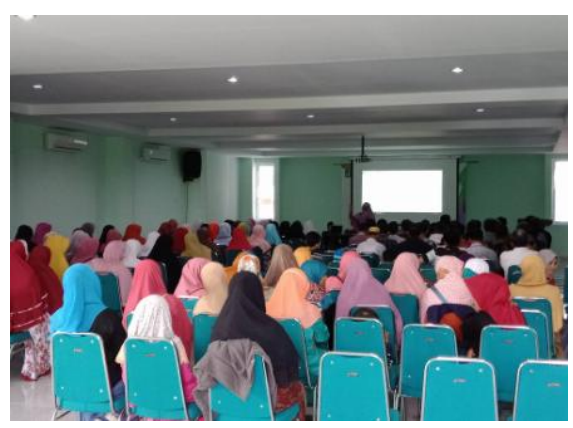

Parenting Skill

\section{SIMPULAN}

Hasil penelitian menunjukkan bahwa partisipasi orang tua sangat diperlukan untuk menciptakan dan meningkatkan budaya positif di sekolah dasar. Adanya kerjasama yang kuat antara pihak sekolah dan orang tua mampu mempengaruhi keberhasilan terciptanya budaya positif yang tidak hanya berdampak pada sekolah seperti: meningkatnya mutu sekolah, sarana sosialiasi kegiatan sekolah dan pembentukan sikap peserta didik, tetapi juga pada orang tua dalam memberikan dukungan dan mitivasi positif pada peserta didik untuk meningkatkan prestasi dan potensi peserta didik. Bentuk partisipasi orang tua yaitu melakukan kegiatan rutin yang diadakan oleh pihak sekolah, seperti: Kajian Kelas, Family Gathering, Parenting skill, Family Day, Sarasehan Ramadhan

\section{DAFTAR PUSTAKA}

Espericueta . (2015). Creating a Positive School Environment From the Outside. Diunduh dari https://www.pearsoned.com/creating-a-positive-schoolenvironment-from-the-outside-in/ pada 30 Juli 2018.

Habbeger. (2008). The Principal's Rile in Successful School: Creating A Positive School Culture. Diakses dari https://www.naesp.org/sites/default/files/resources/1/Principal/2008/S-O p42.pdf pada 25 Juni 2015.

Henderson, A. T., \& Berla, N. (2004). A new generation of evidence: The family is critical to student achievement. Washington DC. National Committee for Citizen in Education. 
Mutch \& Collins. (2012). Partners in Learning: Schools' Engagement WithParents, Families, and Communities in New Zealand Carol Mutch and Sandra Collins. Diunduh dari www.adi.org/journal/2012ss/mutchcollinsspring2012.pdf pada 30 Juli 2018.

Stolp, S. (1994) Leadership for School Culture. ERIC Digest, Number 91.

Sugiyono. (2017). Metode Penelitian Pendidikan (Pendekatan Kuantitatif, Kualitatif, dan $R \& D)$. Bandung: Alfabeta.

Tika, Moh. Pabundu. 2005. Metode Penelitian Geografi. Bumi Aksara. Jakarta

Zubaidah. (2015). Pengaruh Budaya Sekolah dan Motivasi Kerja Guru terhadapa Mutu Pendidikan di SMKN 1 Pabelan. Diakses dari https://media.neliti.com/media/publications/170867-ID-pengaruh-budaya-sekolahdan-motivasi-ker.pdf pada 26 Juni 2018. 